\title{
Self-Medication for Oral Health Problems among Dental Outpatients at a Nigerian Tertiary Hospital
}

\author{
Adetokunbo Olawuyi ${ }^{1}$, Lateef Ibrahim ${ }^{1}$, Omolara Uti $^{2}$ \\ ${ }^{1}$ Department of Oral and Maxillofacial Pathology/Biology, Lagos University Teaching Hospital, Surulere, Lagos State, Nigeria \\ ${ }^{2}$ Department of Preventive Dentistry, College of Medicine, University of Lagos, Lagos, Nigeria \\ Email: *olawuyitoks@gmail.com
}

How to cite this paper: Olawuyi, A., Ibrahim, L. and Uti, O. (2019) Self-Medication for Oral Health Problems among Dental Outpatients at a Nigerian Tertiary Hospital. Open Journal of Stomatology, 9, 9-20. https://doi.org/10.4236/ojst.2019.91002

Received: November 9, 2018

Accepted: December 22, 2018

Published: December 25, 2018

Copyright (c) 2019 by authors and Scientific Research Publishing Inc. This work is licensed under the Creative Commons Attribution International License (CC BY 4.0).

http://creativecommons.org/licenses/by/4.0/

\section{(c) (i) Open Access}

\begin{abstract}
Background: Self-medication is the inappropriate use of drugs to treat self-diagnosed disorders or symptoms. Even though Self-medication has benefits as it enhances better use of clinical skills and increases access to medication; it is also associated with risks such as adverse drug reactions and antibiotics resistance. Objectives: To determine prevalence of self-medication practices among dental out-patients, triggering factors that influence self-medication practice and common source of drugs. Materials and methods: This descriptive cross-sectional study was conducted at the Clinic of the Department of Preventive Dentistry, Lagos University Teaching Hospital over a period of 6 months using self-administered questionnaires adapted from previous studies. Data obtained was analysed and expressed as frequencies and percentages. Test of associations was done using chi-square $(\mathrm{p}<0.05)$. Results: Age of respondents ranged from 16 to 78 years $(32.24 \pm 13.47)$. M:F was 1:1. Prevalence of self-medication was $45.5 \%$; toothache was the most prevalent reason for self-medication (71\%). The frequently used drugs for self-medication were analgesics (65\%) while the most common source for the drugs was the pharmacy $(60 \%)$. Educational status $\left(\mathrm{X}^{2}=12.85, \mathrm{P}<0.05\right)$, gender $\left(\mathrm{X}^{2}=6.42, \mathrm{P}<0.05\right)$ and likelihood of recommending drugs to family and friends $\left(\mathrm{X}^{2}=10.38, \mathrm{P}<0.05\right)$ were significantly associated with self-medication. Conclusion: This study revealed high prevalence of self-medication with toothache as the predominant trigger and pharmacy, the most common source.
\end{abstract}

\section{Keywords}

Self-Medication, Toothache, Oral Health 


\section{Introduction}

Self-medication has been defined as the inappropriate use of drugs to treat self-diagnosed disorders or symptoms of a disease, or the intermittent or continued use of a prescribed medication for chronic or recurrent disease or symptoms [1] [2]. It is seen as the "desire and ability of people/patients to play an intelligent, independent and informed role, not merely in terms of decision-making but also in the management of those preventive, diagnostic and therapeutic activities which concern them" [3] [4].

Several reasons have been given for self-medication: Urge of self-care, lack of time, lack of access to healthcare services, easy access to drugs, previous prescription of the drug, lack of transportation, lack of finance, ignorance, extensive advertisement, feeling of sympathy towards a family member in sickness and wanting to avoid the complexity associated with orthodox treatment [5] [6]. Regardless of the reasons being adduced for the increasing adoption of self-medication globally, it is important to bear in mind that it is a double-edged sword for its users, because it has both beneficial and harmful effects [7].

Self-medication has its own benefits as it enhances better use of clinical skills, increases access to medication and may contribute to reducing prescribed drug costs associated with publicly funded health programmes [8] [9]. Some of the risks associated with self-medication include: severe drug reactions, dangerous drug interaction, increasing antibiotics resistance, drug abuse and dependence, misdiagnosis, renal dysfunction and incorrect administration of drugs [9] [10] [11].

Toothache is one of the commonest clinical presentations. It is common knowledge among dentists that patients resort to taking drugs, most especially analgesic and antibiotics in order to experience temporary relief or to avoid the need for dental consultation and treatment [12] [13]. Sofola et al. reported that $85.1 \%$ of patients older than 16 years applied at least one lay measure in response to oral pain [14].

Drug retail shops and pharmacies are a regular feature in many Nigerian cities where prescription drugs are readily available over the counter in contrast to developed countries where strict criteria are in place to dispense drugs. These outlets are the first point of call for many patients and play a major role in encouraging self-medication among Nigerians.

While responsible self-medication is a critical component of self-care, there is a tendency for patients to resort to inappropriate self-medication. Data on current practices about self-medication for dental conditions is considered to be of vital importance for policy formulation. Information on self-medication practices for dental problems in Lagos, Nigeria is not available in the scientific literature. Therefore, the present study aims to determine the trends in self-medication for dental problems among patients attending the dental clinic at the Lagos University Teaching Hospital, Lagos Nigeria. 


\section{Methodology}

\subsection{Study Population}

The descriptive cross-sectional study was conducted at Clinic of the Department of Preventive Dentistry, Lagos University Teaching Hospital, Lagos State, between October and March 2018.

Subjects who were 18 years and above presenting at the Oral diagnosis clinic were included in the study while those unwilling to participate and subjects who were mentally incapacitated were excluded from the study.

\subsection{Ethical Clearance}

Ethical approval for this study was obtained from the Health Research and Ethics Committee of the Lagos University Teaching Hospital for confidentiality and use of data. The study was conducted after obtaining written informed consent from participants who satisfied the inclusion criteria.

\subsection{Sample Size Determination}

Sample size was calculated using the formula:

$$
n=\frac{Z^{2} p q}{d^{2}}
$$

$N=$ the estimate of the population size, $Z=$ Critical value at the level of the chosen confidence level. $d^{2}=$ the precision level set at 0.05. $P=$ estimated proportion of an attribute that is present in the population $=70 \%{ }^{4}=0.70 . q=1-p$ $=0.30$.

$Z=1.96$ Standard error at $95 \%$ level of Confidence.

At 95\% confidence level, $Z=1.96, p=0.70, q=1-0.70=0.30, d=0.05$.

Therefore,

$$
n=\frac{Z^{2} p q}{d^{2}}-\frac{(1.96)^{2} * 0.70 * 0.30}{(0.05)^{2}}=322
$$

Addition of 10\% for non-response: $322+32=354$.

\subsection{Data Collection}

The study was carried out using self-administered questionnaires in English, adapted from previous similar studies [12] [17]. It was closed-ended containing 26 questions, under two sections. First section of the questionnaire contained information related to demographic details of the survey participants; Second section of the questionnaire contains information related to distance of the respondent's houses from the nearest health care centre/clinic/medical store, last dental visit, common dental problems requiring self-medication, frequently used drugs for self-medication, triggering factors and sources of information about medications used and reasons for self-medication as well as source.

\subsection{Data Processing and Analysis}

Data obtained was analysed with Statistical Package for Social Science (SPSS ver- 
sion 18.0) and expressed as frequencies and percentages in tables and charts as appropriate. Tests of associations was done using chi-square $(\mathrm{p}<0.05)$.

\section{Result}

\subsection{Demographic Details of the Population}

A total of 400 patients enrolled in the study. Age of respondents ranged from 16 to 78 years $(32.24 \pm 13.47)$. There were more respondents in the third decade 195 (48.8\%), while M:F was 1:1. Out of 193 who volunteered information on their monthly income, 120 (62.3\%) earned N50,000 and above, 67 (34.7\%) earned N20,000 - N50,000 and 6 (3\%) earned less than N20,000. On the distribution of participants based on educational qualification, 278 (69.5\%) were graduates, 68 (17\%) had a diploma, the rest were Senior School Certificate (SSC) 41 (10.2\%), PreSSC 8 (2.0\%), while $5(1.3 \%)$ of respondents were illiterates, $0.3 \%$ were unemployed and $8 \%$ undertook unskilled work (Table 1).

About half of respondents (51\%) live more than $2 \mathrm{~km}$ from the nearest Dental clinic.

\subsection{Self-Medication Practice for Oral Problems}

One hundred and eighty two respondents (45.5\%) practice self-medication; among this one hundred and eighty two who practice self-medication, 67 respondents (36.8\%) self-medicated more than twice in the past 6 months. Toothache was the most prevalent reason for self-medication $130(71 \%)$, followed by gum problems $24(13.1 \%)$, swelling in the face $13(7.1 \%)$, bad breath $12(6.6 \%)$ and mobile tooth $3(1.6 \%)$.

The frequently used drugs for self-medication were analgesics 118 (65\%), antibiotics 27 (15\%), native herbs 25 (14\%), salt and water $12(6 \%)$ and $100(55 \%)$ said the drugs were effective while $82(45 \%)$ had temporary relief. The most common source for the drugs was the pharmacy 110 (60\%) (Table 2).

Eighty-two of the respondents who practice self-medication took the drugs because they had a previous prescription $82(45 \%)$ while lack of finance 75 (41.5\%) and advice from family and friends 25 (13.5\%) were the other reasons. In addition to taking medications without prescription; one hundred and sixteen of the respondents (64\%) admitted they also recommend medications for family and friends.

Three hundred and twenty of the participants (80\%) in this study believe that self-medication may be dangerous.

\subsection{Associations with Self Medication}

Examination of the effects of sociodemograhic characteristics revealed that educational status $\left(\mathrm{X}^{2}=12.85, \mathrm{P}<0.05\right)$ and gender $\left(\mathrm{X}^{2}=6.42, \mathrm{P}<0.05\right)$ were significantly associated with self-medication. There was also a significant association of self-medication practice with the likelihood of recommending drugs to family and friends $\left(\mathrm{X}^{2}=10.38, \mathrm{P}<0.05\right)$ (Table 3$)$. 
Table 1. Socio-demographic characteristics of respondents.

\begin{tabular}{|c|c|c|}
\hline VARIABLE & FREQUENCY & PERCENT \\
\hline \multicolumn{3}{|l|}{ Age (years) } \\
\hline $11-20$ & 46 & 11.5 \\
\hline $21-30$ & 195 & 48.8 \\
\hline $31-40$ & 79 & 19.8 \\
\hline $41-50$ & 33 & 8.3 \\
\hline $51-60$ & 21 & 5.3 \\
\hline $61-70$ & 19 & 4.8 \\
\hline $71-80$ & 7 & 1.8 \\
\hline \multicolumn{3}{|l|}{ Mean Age - 32.24 years } \\
\hline \multicolumn{3}{|c|}{ Standard Deviation - 13.47} \\
\hline Total & 400 & 100 \\
\hline \multicolumn{3}{|l|}{ Gender } \\
\hline Female & 203 & 50.8 \\
\hline Male & 197 & 49.3 \\
\hline Total & 400 & 100 \\
\hline \multicolumn{3}{|l|}{ Occupation } \\
\hline Skilled & 173 & 43.3 \\
\hline Unskilled & 32 & 8.0 \\
\hline Business & 58 & 14.5 \\
\hline Student & 136 & 34 \\
\hline Unemployed & 1 & 0.3 \\
\hline Total & 400 & 100 \\
\hline \multicolumn{3}{|l|}{ Educational status } \\
\hline Graduate & 278 & 69.5 \\
\hline Diploma & 68 & 17.0 \\
\hline SSC & 41 & 10.2 \\
\hline PreSSC & 8 & 2.0 \\
\hline No Education & 5 & 1.3 \\
\hline Total & 400 & 100 \\
\hline \multicolumn{3}{|l|}{ Monthly income } \\
\hline Less than $\# 20,000$ & 6 & 3 \\
\hline$\# 20,000$ - \#50,000 & 67 & 34.7 \\
\hline More than $\# 50,000$ & 120 & 62.3 \\
\hline TOTAL & 193 & 100 \\
\hline
\end{tabular}

\section{Discussion}

The present study aimed to study the trends in self-medication practices among 
Table 2. Self-medication practice for oral problems.

\begin{tabular}{|c|c|c|}
\hline VARIABLE & FREQUENCY & PERCENTAGE \\
\hline \multicolumn{3}{|l|}{ Self-Medication } \\
\hline Yes & 182 & 45.5 \\
\hline No & 218 & 54.5 \\
\hline Total & 400 & 100 \\
\hline \multicolumn{3}{|l|}{ Triggering Factors } \\
\hline Toothache & 130 & 71 \\
\hline Gum Problems & 24 & 13.1 \\
\hline Facial Swelling & 13 & 7.1 \\
\hline Bad Breath & 12 & 6.6 \\
\hline Mobile Tooth & 3 & 1.6 \\
\hline Total & 182 & 100 \\
\hline \multicolumn{3}{|l|}{ Type of Medication } \\
\hline Analgesics & 118 & 65 \\
\hline Antibiotics & 27 & 15 \\
\hline Native Herbs & 25 & 14 \\
\hline Salt and Water & 12 & 6 \\
\hline Total & 182 & 100 \\
\hline \multicolumn{3}{|l|}{ Source of Medication } \\
\hline Pharmacy & 110 & 60 \\
\hline Local drug store & 22 & 12 \\
\hline Tradomedical Store & 20 & 11.5 \\
\hline Family and Friends & 30 & 16.5 \\
\hline Total & 182 & 100 \\
\hline \multicolumn{3}{|c|}{ Reason for Self-Medication } \\
\hline Previous Prescription & 82 & 45 \\
\hline Lack of Finance & 75 & 41.5 \\
\hline Advice from Family & 25 & 13.5 \\
\hline TOTAL & 182 & 100 \\
\hline
\end{tabular}

patients attending the clinic for oral health problems. In Nigeria prescription drugs are readily available over-the-counter, in contrast to developed countries, where strict criteria are in place to dispense drugs.

The age range of respondents in this study is from 16 to 78 years. However, almost half of the respondents (48.8\%) are in the third decade of life. The peak age-group in this study is similar to other previous hospital-based studies [15] [16]. This age-group in most populations constitute the work-force and are more susceptible to stress and therefore tries to adopt self-medication practices due to various factors like lack of money, time, minor illness and previous experience of 
Table 3. Associations with self-medication.

\begin{tabular}{|c|c|c|c|c|c|c|}
\hline VARIABLE & Self- $N$ & edication & & $\mathrm{DF}$ & $\mathrm{X}^{2}$ & P-VALUE \\
\hline \multirow{2}{*}{ Educational status } & No & Yes & Total & 10 & 12.85 & ${ }^{*} 0.03$ \\
\hline & Number [Percent] & \multicolumn{2}{|c|}{ Number [Percent] } & & & \\
\hline Graduate & $145[52]$ & $133[48]$ & 278 & & & \\
\hline Diploma & $26[38]$ & $42[62]$ & 68 & & & \\
\hline SSC & $26[63]$ & $15[37]$ & 41 & & & \\
\hline PreSSC & $3[37]$ & $5[63]$ & 8 & & & \\
\hline No Education & $3[60]$ & $2[40]$ & 5 & & & \\
\hline Occupation & & & & 10 & 9.55 & 0.14 \\
\hline Skilled & $93[54]$ & $80[46]$ & 173 & & & \\
\hline Unskilled & $17[53]$ & $15[47]$ & 32 & & & \\
\hline Student & $31[53]$ & $27[47]$ & 58 & & & \\
\hline Buisness & $63[46]$ & $73[54]$ & 136 & & & \\
\hline Unemployed & $1[100]$ & $0[0]$ & 1 & & & \\
\hline Gender & & & & 2 & 6.42 & $* 0.04$ \\
\hline Male & $125[63]$ & $72[37]$ & 197 & & & \\
\hline Female & $93[46]$ & $110[54]$ & 203 & & & \\
\hline $\begin{array}{l}\text { Likelihood of } \\
\text { Recommending } \\
\text { drugs }\end{array}$ & & & & 4 & 10.38 & ${ }^{*} 0.01$ \\
\hline Yes & $37[32]$ & $80[68]$ & 117 & & & \\
\hline No & $139[70]$ & $102[30]$ & 241 & & & \\
\hline Monthly Income & & & & 6 & 4.81 & 0.29 \\
\hline Less than \#20,000 & $3[50]$ & $3[50]$ & 6 & & & \\
\hline$\# 20,000$ - \#50,000 & $35[53]$ & $32[47]$ & 67 & & & \\
\hline More than $\# 50,000$ & $61[51]$ & $59[49]$ & 120 & & & \\
\hline
\end{tabular}

treating a similar illness [17].

In this study, the prevalence of self-medication was $45.5 \%$, which is much lower than $100 \%, 76 \%$ and $70 \%$ reported from similar studies conducted in Bangalore [17] Pakistan [12] and India [13] respectively. The high prevalence of self-medication in these studies have been attributed to different reasons such as distance from nearest health post/medical store, minor illness, lack of time, quick relief from symptoms, no family support, lack of knowledge about side effects, and belief in other herbal system of medicines [17].

There was a significant association between gender and self-medication in the present study; observations in our survey that $54 \%$ of females practice self-medication compared to $37 \%$ of males is in agreement with a study in Jimma town, Nigeria [18] that reported a self-medication prevalence of $61.9 \%$ among females. However, a similar study conducted in Bangalore reported a higher 
prevalence in males. The high prevalence of self-medication practice among females in the present study may be due to their lower threshold for pain and fear of dental treatment as compared to males [12].

There was a positive association in level of education of respondents and self-medication practice in this study similar to findings from other studies [12] [19] The high prevalence noticed among patients with university education (graduates), may be due to the fact that education makes people confident of self-medication and also gives the ability to read drug labels while respondents who are illiterate may not know the common drug names and have challenges understanding instructions on drug labels [12].

This study also revealed toothache $(71 \%)$ as the most common dental problem that necessitates most patients to self-medicate in agreement with previous studies [12] [19] Majority of respondents in this study (45\%) offers that the knowledge of previous medication is the reason why they use drugs without prescription. It is likely that some patients either keep the case of previously prescribed drugs or master the colour to be able to procure same for similar future dental problems.

Similarly, this study shows that the commonest abused drugs among dental patient are analgesics (65\%), similar to reports from another study [16]. This trend is in conformity with previous observation that toothache is the commonest problems among dental patients, so it is reasonable that they turn to use of analgesics, which are readily available as over-the-counter drugs.

There was an association between self-medication and likelihood of recommending prescription of drugs to family and friends in this survey signifying that while people have a high tendency of undertaking self-medication, they also propagate this flawed practice by recommending drugs to others. More than two-third of the respondents, 320 (80\%) believe that self-medication may be hazardous, which was a similar finding reported earlier in literature [19]. While self-medication has benefits, there are hazards associated with it, some of which include: drug reactions and interactions, mounting antibiotics resistance, drug abuse and dependence which is a major challenge in Nigeria, misdiagnosis and renal dysfunction [9] [11].

\section{Conclusion}

The prevalence of self-medication in this study is relatively high and should be a source of concern for health care practitioners. The dangers associated with self-medication cannot be over-emphasized. This study concluded that self-medication practices were more prevalent among females and university graduates. It is therefore important to embark on health education to enlighten the populace on responsible use of drugs and ensure that there are laws to prevent indiscriminate purchase and use of medications from drug outlets.

\section{Limitations of the Study}

The study has some limitations; the first is that cross-sectional design of this 
study does not allow for causal inference. Secondly, the study population was made up of only patients seeking dental consultation, hence the results presented here may not be a true representation of the general population.

\section{Conflicts of Interest}

There are no conflicts of interest to disclose.

\section{References}

[1] Luis Turabián, J. and Ramón de Juanes, J. (1989) Self-Medication and Pharmacologic Compliance at a Primary Care Center. Gaceta Sanitaria, 3, 510-515. https://doi.org/10.1016/S0213-9111(89)70974-2

[2] Hartlová, S. and Solich, J. (1990) Drugs and Health Awareness in the Population. Cesk Zdrav, 38, 120-126.

[3] Laporte, J.R. and Castel, J.M. (1992) The Physician and Self-Medication. MedinicaClinica, 99, 414-416.

[4] Laporte, J.R. (1997) Self-Medication: Does Information to Users Increase at the Same Rate as Consumption. Medinica Clinica, 109, 795-796.

[5] Bennadi, D. (2013) Self-Medication: A Current Challenge. Journal of Basic and Clinical Pharmacy, 5, 19-21. https://doi.org/10.4103/0976-0105.128253

[6] Azami-Aghdash, S., Mohseni, M., Etemadi, M., Royani, S., Moosavi, A. and Nakhaee, M. (2015) Prevalence and Cause of Self-Medication in Iran: A Systematic Review and Meta-Analysis Article. Iranian Journal of Public Health, 44, 580-586.

[7] Marak, A., Borah, M., Bhattacharyya, H. and Talukdar, K. (2016) A Cross-Sectional Study on Self-Medication Practices among the Rural Population of Meghalaya. International Journal of Medical Science and Public Health, 5, 1134-1138. https://doi.org/10.5455/ijmsph.2016.17072015160

[8] Hughes, C.M., McElnay, J.C. and Fleming, G.F. (2001) Benefits and Risks of Self-Medication. Drug Safety, 24, 1027-1037. ttps://doi.org/10.2165/00002018-200124140-00002

[9] Ruiz, M.E. (2010) Risks of Self-Medication Practices. Current Drug Safety, 5, 315-323. https://doi.org/10.2174/157488610792245966

[10] Syed, N., Naseer, M., Memon, M.Q. and Rani, K. (2014) Prevalence of Self-Medication and Its Practice among the Medical and Non-Medical Students. Journal of Liaquat University of Medical Sciences, 13, 79-84.

[11] Shamaila Saleem, M.N. (2015) Self-Medication Practice among First Year Medical Students in University College of Medicine and Dentistry, University Of Lahore. Pakistan Journal of Physiology, 1, 20-21.

[12] Baig, Q.A., Muzaffar, D., Afaq, A., Bilal, S. and Iqbal, N. (2012) Prevalence of Self-Medication among Dental Patients. Pakistan Oral \& Dental Journal, 32, 34-38.

[13] Kalyan, V.S., Sudhakar, K., Srinivas, P., Sudhakar, G., Pratap, K. and Padma, T.M. (2013) Evaluation of Self-Medication Practices among Undergraduate Dental Students of a Tertiary Care Teaching Dental Hospital in South India. Journal of Education, Ethics and Dentistry, 3, 21-25. https://doi.org/10.4103/0974-7761.126939

[14] Sofola, O.O. and Uti, O.G. (2009) Coping with Oral Pain: Lay Management Strategies Adopted by Patients Prior to Presentation. Nigerian Quarterly Journal of Hospital Medicine, 19, 43-49. 
[15] Anyanechi, C.E. and Saheeb, B.D. (2015) Toothache and Self-Medication Practices: A Study of Patients Attending a Niger Delta Tertiary Hospital in Nigeria. Annals of Medical and Health Sciences Research, 4, 884-888.

[16] Buke, C., Limoncu, M., Ermevtcan, S., Ciceklioglu, M., Tuncel, M., Kose, T., et al. (2005) Irrational Use of Antibiotics among University Students. Journal of Infection, 51, 135-139. https://doi.org/10.1016/j.jinf.2004.12.001

[17] Komal Raj, M.R., Padma, K.B. and Aruna, C.N. (2015) Self-Medication Practices for Oral Health Problems among Dental Patients in Bangalore: A Cross-Sectional Study. IOSR Journal of Pharmacy, 10, 68-75.

[18] Worku, S. and Mariam, A.G. (2003) Practice of Self-Medication in Jimma Town, Nigeria. Ethiopian. Journal of Health Development, 17, 111-116.

[19] Shankar, P.R., Partha, P. and Shenoy, N. (2002) Self-Medication and Non-Doctor Prescription Practices in Pokhara Valley, Western Nepal: A Questionnaire-Based Study. BMC Family Practice, 3, 17-22. https://doi.org/10.1186/1471-2296-3-17 


\section{Appendix 1}

\section{Self Medication among Patients Attending the Dental Clinic of the Lagos University Teaching Hospital}

This questionnaire is designed to study the pattern of self-medication among patients attending the dental clinic of the Lagos University Teaching hospital, Lagos State, Nigeria.

The information provided by the respondents is strictly confidential. Thank you!

\section{Section A}

1) Serial No:

2) Residential Address (LG):

3) Age:

4) Income (Monthly)

5) Sex:

6) Ethnicity (a) Yoruba (b) Igbo (c) Hausa (d) Others (specify)

7) Educational status: (a) None (b) Primary (c) Secondary (d) OND/HND

(e) University (f) Masters/Post graduate (g) Others (please specify)

8) Occupation:

9) Religion (a) Christian (b) Muslim (c) Others (please specify)

\section{Section B}

9) How far is your house from the nearest dental clinic?
(a) $<1 \mathrm{~km}$
(b) $1-2 \mathrm{~km}$
(c) $>2 \mathrm{~km}$

10) Is this your first visit to the dental clinic. (a) Yes

(b) No

11) When was your last dental visit?

12) Did you have any dental problems in the last one month? (a) Yes

(b) No

13) If yes to Question 12, what problems

14) What was done to treat the problem.
(a) Took medications on my own
(b) Went to the dental clinic
(c) Went to the chemist (d) used herbal products

15) If the dental problem was treated, where was it treated

16) Do you take medications without doctor's prescription? (a) Yes $\quad$ (b) No

17) How many times in the last month did you takes medications without Doctor's prescription? (a) Once $\quad$ (b) Twice $\quad$ (c) More than two times

18) Will you undertake self-medication if you have dental problems in the next
six months? (a) No
(b) Likely
(c) Very likely
(d) Not sure 
19) For what dental problems do you self-medicate.
(a) Toothache
(b) Gum bleeding
(c) Bad breath
(d) facial swelling
(e) Tooth mobility
(f) Others (Please specify)

20) Why do you self-medicate?
(a) Lack of access to dental services
(b) Lack of finance
(c) Previous prescription of the drug $\quad$ (d) Lack of transportation $\quad$ (e) Traditional/Religious belief (f) Unavailability of doctors (g) Advice from family/friends (h) advertisement

21) How do you feel after taking medications?
(a) Temporary relief
(b) Effective
(c) Useful in stressful situation
(d) Unsure about the effect

22) Which of these medications do you normally take without doctor's prescription? Please give name of the $\operatorname{drug}(\mathrm{s})$
(a) Analgesics
(b) Native herbs
(c)Antibiotics
(d) Salt and hot water
(e) Others (Please specify)

23) Who recommends drugs for you?
(a) Relatives
(b) Friends
(c) Personal knowledge
(d) Pharmacist
(e) Mass media
(f) Traditional healer
(g) Others (Please specify)

24) If you take medications without doctor's prescription, where do you normally get the drugs and instructions for their use?
(a) Pharmacy
(b) Chemist (c) Hospital Pharmacy
(d) Traditional Home
(e) family and friends
(f) Others (Please specify)
25) Do you recommend drugs for family and friends (a) Yes
(b) No
26) Do you think self-medication is dangerous? (a)Yes
(b) No 